\title{
Extraction of Nanosized Cobalt Sulfide from Spent Hydrocracking Catalyst
}

\author{
Samia A. Kosa ${ }^{1}$ and Eman Z. Hegazy ${ }^{1,2}$ \\ ${ }^{1}$ Chemistry Department, Faculty of Science, King Abdulaziz University, Jeddah, Saudi Arabia \\ ${ }^{2}$ National Research Center, Dokki, Cairo, Egypt \\ Correspondence should be addressed to Eman Z. Hegazy; ehegazy77@yahoo.com
}

Received 30 December 2012; Revised 1 February 2013; Accepted 6 March 2013

Academic Editor: Tianxi Liu

Copyright (c) 2013 S. A. Kosa and E. Z. Hegazy. This is an open access article distributed under the Creative Commons Attribution License, which permits unrestricted use, distribution, and reproduction in any medium, provided the original work is properly cited.

The processes used for the extraction of metals (Co, Mo, and $\mathrm{Al}$ ) from spent hydrotreating catalysts were investigated in this study. A detailed mechanism of the metal extraction process is described. Additionally, a simulation study was performed to understand the sulfidizing mechanism. The suggested separation procedure was effective and achieved an extraction of approximately $80-90 \%$. In addition, the sulfidization mechanism was identified. This sulfidizing process for Co was found to involve an intermediate, the structure of which was proposed. This proposed intermediate was confirmed through simulations. Moreover, the activities of the spent and the regenerated catalyst were examined in the cracking of toluene. The modification of the spent catalyst through the use of different iron oxide loadings improved the catalytic activity.

\section{Introduction}

In the past, oil refining companies used to dispose of spent catalysts by burning off the entrained carbon, sulfur, and hydrocarbons. The resulting material could then be sold to iron and steel producers as a relatively inexpensive source of cobalt, molybdenum, and nickel. This method started to lose favor in the 1970s, when refiners stopped using the stripping step due to the increasing costs involved. Unfortunately, sulfur is not favored by steel makers because of the problems it causes, and they also do not like carbon in the form in which it is found in spent catalysts. As a result, untreated spent catalysts were no longer of value to smelters; thus, instead of being usable waste, the spent catalysts were encapsulated by the oil refining companies before being sent to landfills.

These techniques were universally banned by the mid1980 s because these catalysts contributed to the environmental pollution of air, soil, and oceans. Thus, the contamination of these environments by these catalysts became a serious global problem. A recent memorandum by the U.S.
Environmental Protection Agency (EPA) stated that spent catalysts are hazardous waste. As a result, the improper classification of such catalysts could become a litigation nightmare for refiners. Therefore, in November 1999, the EPA clarified the referenced memorandum to characterize spent hydroprocessing catalysts as hazardous waste subject to the regulations mandated by the Resource Conservation and Recovery Act (RCRA) subtitle C (2).

As a result, some spent catalysts may soon be classified as hazardous toxic waste, which means that these catalysts will require additional treatment to comply with the required strict controls for their handling and disposal [1]. Moreover, molybdenum and cobalt are in high demand for use in alloy steel, aircraft parts, armor, industrial motors, filaments, and various grades of pigments $[2,3]$. Due to the increasing demand for these metals in the industrial market, many approaches, including acid leaching sulfidization, have been suggested for the recovery of these metals from spent catalysts $[4,5]$. Additionally, bioleaching processes have been used by many researchers [6-10] for the extraction of metals, such as 


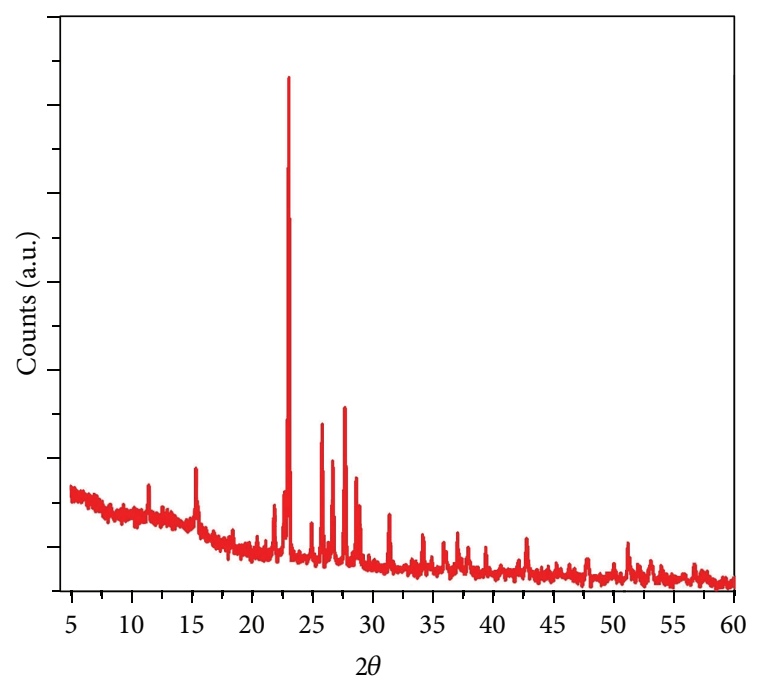

FIGURE 1: XRD of cobalt sulfide sample.

TABLE 1: Concentration of oxalic acid used in the extraction.

\begin{tabular}{lc}
\hline $\begin{array}{l}\text { Oxalic acid/spent catalyst } \\
\text { (mole/g) }\end{array}$ & \% Remaining undissolved solid \\
\hline 0.02 & 40 \\
0.05 & 20 \\
0.075 & 15.5 \\
0.1 & 0.0 \\
\hline
\end{tabular}

TABLE 2: Extraction analysis of Spent catalyst and Extracted metal oxide.

\begin{tabular}{lcccc}
\hline \multirow{2}{*}{ Sample } & \multicolumn{5}{c}{$\mathrm{Wt} \%$} \\
& $\mathrm{Co}_{3} \mathrm{O}_{4}$ & $\mathrm{Mo}_{2} \mathrm{O}_{5}$ & $\mathrm{Al}_{2} \mathrm{O}_{3}$ & $\begin{array}{c}\% \\
\text { Extraction }\end{array}$ \\
\hline Spent catalyst & 6.5 & 16.9 & 76.6 & \\
Co as cobalt sulfide & 5.9 & - & - & 90.7 \\
Mo as molybdenum oxalate & - & 13.7 & - & 81.06 \\
$\mathrm{Al}$ as $\mathrm{Al}_{2} \mathrm{O}_{3}$ & - & - & 74.8 & 97.65 \\
\hline
\end{tabular}

TABLE 3: EDX analysis of Spent catalyst and Cobalt Sulfide sample.

\begin{tabular}{lcccccc}
\hline Sample & Co & Mo & Al & O & C & S \\
\hline Spent catalyst & 2.71 & 4.15 & 50 & 41.4 & 1.74 & 0 \\
Cobalt sulfide & 16 & 0 & 0.42 & 36.56 & 29.89 & 17.13 \\
\hline
\end{tabular}

$\mathrm{Mo}, \mathrm{Ni}, \mathrm{Co}$, and $\mathrm{V}$, from a variety of spent petroleum catalysts. In these cases, sulfur-oxidizing bacteria play a significant role in the enhancement of the metal leaching efficiencies of the process [11]. However, the main disadvantage of the bioleaching process is that it is very slow compared with other leaching processes.

Cobalt usually forms diverse binary sulfides with the general formula of $\mathrm{CoS}_{x}$, for example, $\mathrm{Co}_{9} \mathrm{~S}_{8}, \mathrm{CoS}, \mathrm{Co}_{3} \mathrm{~S}_{4}$, $\mathrm{Col}_{-x} \mathrm{~S}, \mathrm{Co}_{2} \mathrm{~S}_{3}$, and $\mathrm{CoS}_{2}$. These binary sulfides have attracted attention as a result of their excellent properties and their potential use in the hydrodesulfurization and hydrodearomatization processes that are used in various industrial fields [12]. Of these cobalt sulfides, $\mathrm{Co}_{3} \mathrm{~S}_{4}$ (linnaeite) has a normal spinel structure (space group $F d 3 m$ ) in which Co atoms occupy both the tetrahedral (A) and the octahedral (B) sites. It has been reported that $\mathrm{Co}_{3} \mathrm{~S}_{4}$ exhibits an antiferromagnetic $(\mathrm{AF})$ order of less than $\mathrm{TN}=58 \mathrm{~K}$ [11]. Conventionally, cobalt sulfide powders are prepared using solid-state methods. For instance, cobalt sulfide can be produced by the reaction of cobalt with either sulfur $[13,14]$ or hydrogen sulfide [15] or by the reaction of cobalt monoxide with hydrogen sulfide [16]. To date, many researchers have attempted to prepare metal sulfide nanocrystallites using a solution-phase method [17-21], which allows the exact modulation (i.e., size, shape, and composition at the nanometer scale) of the resultant nanocrystals. $\mathrm{Co}_{9} \mathrm{~S}_{8}$ and $\mathrm{CoS}_{2}$ have been selectively fabricated by the reaction of cobalt chlorides and sodium polysulfide via a toluene thermal process [22], and CoS has been synthesized from the reaction of amorphous cobalt sulfide in a hydrazine solution at $120^{\circ} \mathrm{C}[23]$.

In this paper, we will examine the mechanisms by which metals, particularly cobalt sulfide, are extracted from spent catalysts using different techniques, including simulation programs.

\section{Experimental}

2.1. Materials and Methods. Spent catalysts that had been used in the re-refining of waste lube oil for 10 years (life time) were obtained from a local petroleum company. The following chemicals were used in this study: oxalic acid (molecular weight $=126.07$; Min. assay 99.5\%), ammonium hydroxide solution (Min. assay 33\%), hydrochloric acid (Min. assay $30 \%$ ), ferrous sulfide, and ammonium chloride (Min. assay $33 \%)$.

\subsection{Pretreatment of the Catalyst}

2.2.1. Catalyst Washing. The layers of petroleum derivatives contaminating the spent catalyst were washed with different organic solvents (e.g., ethanol and benzene).

The washed catalyst was heat treated in air to eliminate the carbon and sulfur atoms as $\mathrm{CO}_{2}$ and $\mathrm{SO}_{2}$, respectively [24]. The temperature was first raised from 100 to $350^{\circ} \mathrm{C}$ at a rate of $50^{\circ} \mathrm{C} / \mathrm{h}$. The product was then maintained at $350^{\circ} \mathrm{C}$ for $1 \mathrm{~h}$, after which the temperature was increased to $450^{\circ} \mathrm{C}$ at a rate of $25^{\circ} \mathrm{C} / \mathrm{h}$. The product was then maintained at this temperature for $24 \mathrm{~h}$.

2.2.2. Extraction Process. Five grams of the washed spent catalyst was added to $500 \mathrm{~mL}$ of $1 \mathrm{M}$ oxalic acid at $100^{\circ} \mathrm{C}$. The mixture was then maintained at this temperature and stirred for 3 hours. The dissolved catalyst in the solution contains cobalt oxalate, molybdenum oxalate, and aluminum oxalate. To separate the individual metal salts, an aqueous $\mathrm{NH}_{3}$ solution containing $\mathrm{NH}_{4} \mathrm{Cl}$ was added to the mixture to precipitate the group (III) metals as hydroxides, that 


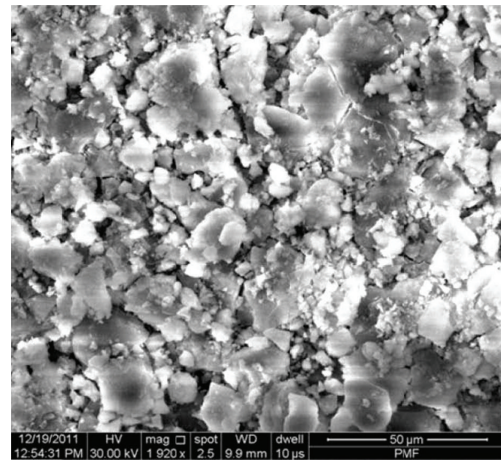

(a)

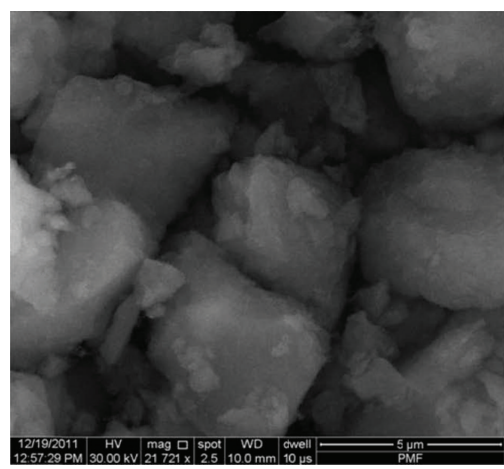

(c)

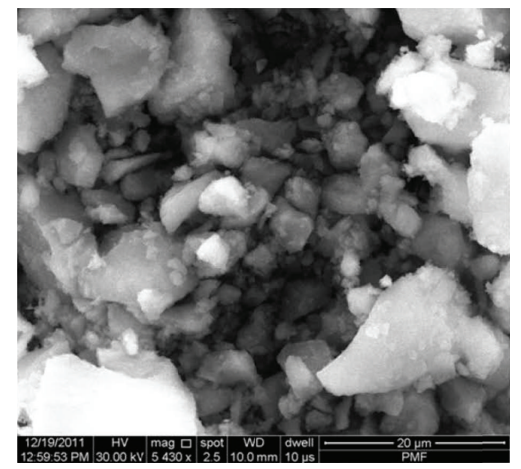

(b)

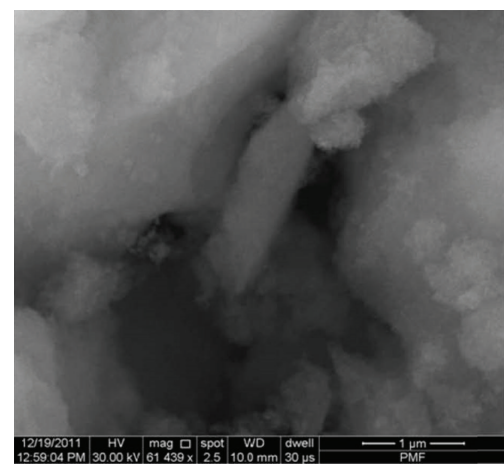

(d)

FIGURE 2: SEM images of spent catalyst at different magnifications.

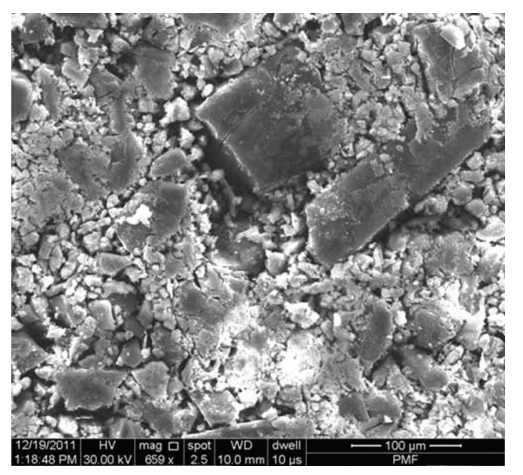

(a)

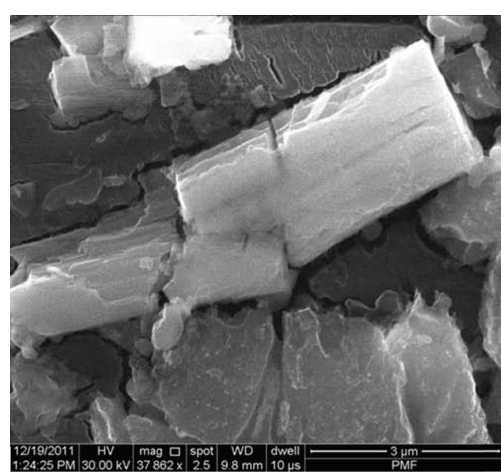

(c)

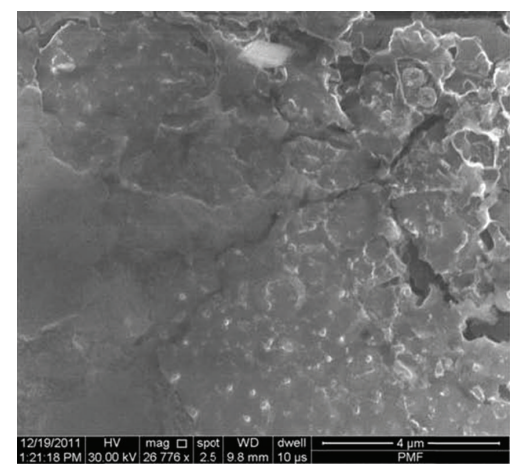

(b)

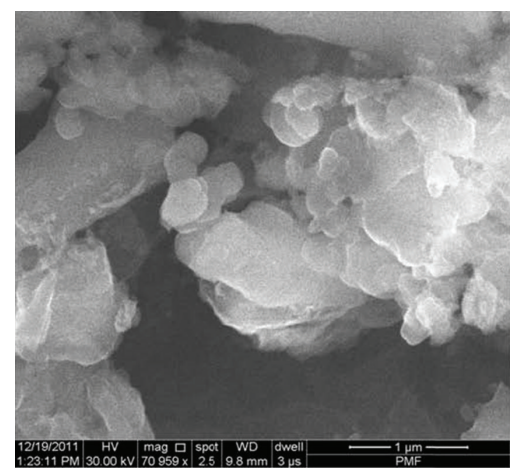

(d)

Figure 3: SEM image of extracted CoS. 


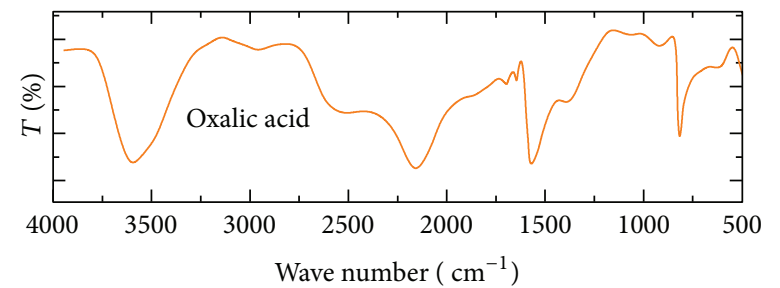

(a)

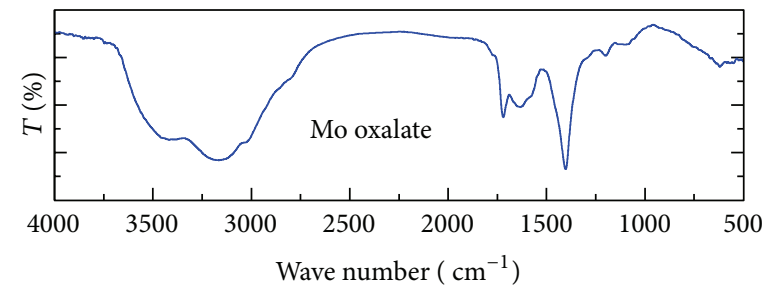

(c)

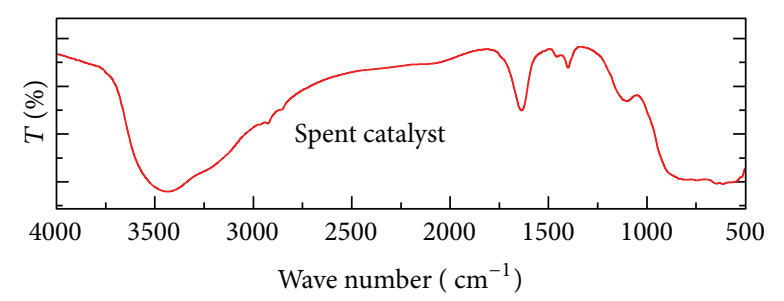

(e)

FIGURE 4: Infrared spectra of spent and all extracted metals.

$\mathrm{Co}^{2+}+\left.\right|_{\mathrm{O}} ^{\mathrm{OOH}}$

Oxalic acid<smiles>CO[18O][18O][Na]</smiles>

Oxalic acid<smiles>CO[N+](C)(O)O</smiles>

Oxalic acid

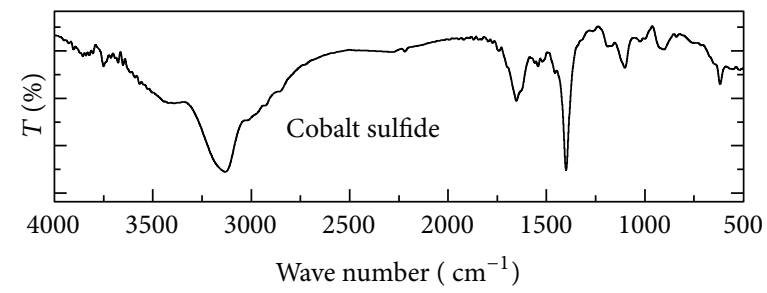

(d)

) (b)

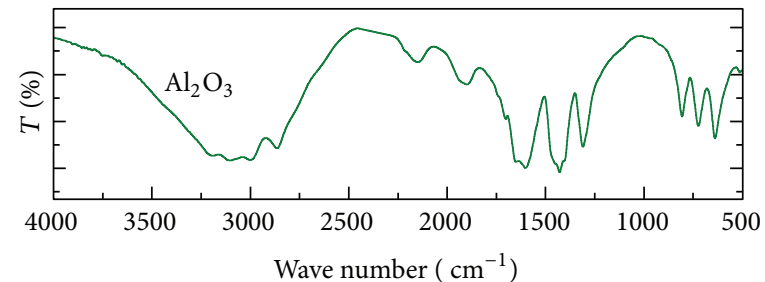




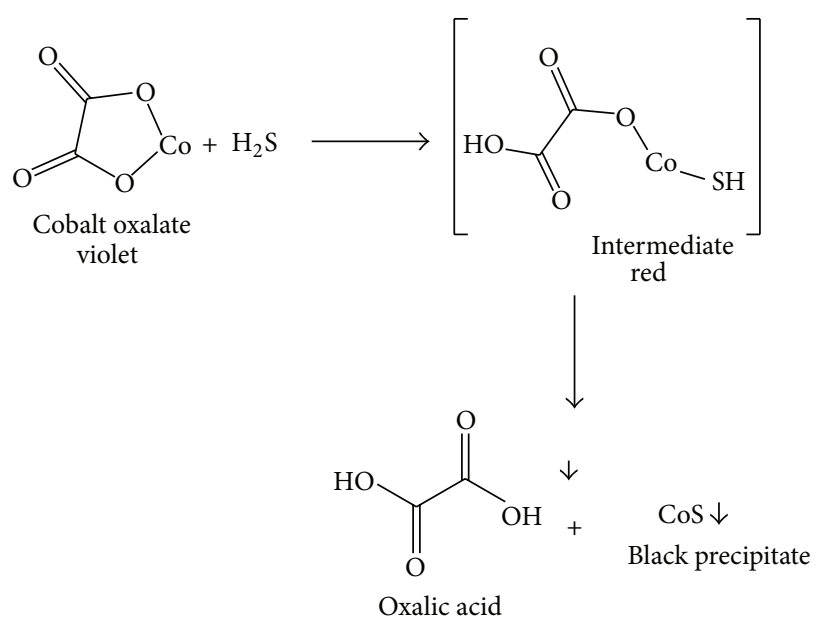

SCHEME 2

is, $\mathrm{Al}(\mathrm{OH})_{3}$. The resulting white gelatinous precipitate was calcined at $1000^{\circ} \mathrm{C}$ to convert it into $\mathrm{Al}_{2} \mathrm{O}_{3}$. The separation of $\mathrm{Co}$ as $\mathrm{CoS}$ was performed by passing $\mathrm{H}_{2} \mathrm{~S}$ gas through the solution. The residual solution containing Mo oxalate was precipitated as white crystals.

The concentrations used and the corresponding solubility of the metals are shown in Table 1.

\subsection{Catalyst Characterizations}

2.3.1. XRD (X-Ray Diffraction Analysis). X-ray diffractograms of the samples under investigation were collected using a Bruker D8 advanced instrument with $\mathrm{CuK} \alpha 1$ radiation and a secondary monochromator, which was operated at $40 \mathrm{kV}$ and $40 \mathrm{~mA}$. The analyses of the crystal lattice and space group were performed using Philips X'Pert Plus V.1.0 23.04. 1999.

2.3.2. SEM and EDX Analysis. The scanning electron microscopy (SEM) images of the different samples and the EDX analysis were performed using a JXA-840 Electron Probe Microanalyzer (Japan).

2.3.3. Elemental Analysis. The elemental analysis was performed using an inductively coupled plasma (ICP) optical emission spectrometer (Model Optima 4100 DV, Perkin Elmer, USA).

2.3.4. Simulation Study. The simulations were performed using the HyperChem 8 software. The energy optimization and calculations were performed based on the PM3 method.

\section{Results and Discussion}

3.1. XRD. The XRD patterns of the spent catalyst and most of the extracted metal solid samples show that these are amorphous (data not included), likely because most of the samples were not calcined at high temperatures. Only the cobalt sulfide samples exhibited a detectable crystalline pattern (Figure 1), which belongs to the sulfur metal phase $\left(\mathrm{S}_{8}\right.$; PDF card no. P741465). This finding can be explained by the fact that the cobalt present in the sample promotes the formation of $\mathrm{S}_{8}$.

3.2. SEM and EDX. SEM images of the spent catalyst at different magnifications are presented in Figure 2, whereas Figure 3 shows an image of $\mathrm{CoS}$ at different magnifications.

These images show that the spent catalysts appear as separate aggregates in an amorphous matrix. This finding can be rationalized by the elemental analysis of the spent catalyst, which shows that it is composed of $76.6 \mathrm{wt} \% \mathrm{Al}_{2} \mathrm{O}_{3}$ (Table 2).

Moreover, the images of the cobalt sulfide sample (Figure 3) showed unidentified agglomerated shapes of cobalt sulfide. A tetragonal shape could be observed as a single separate phase, which could be assigned to the same $S_{8}$ crystal structure that is shown in the XRD patterns.

In addition, the image analysis revealed that the average particle size of CoS is approximately $90 \mathrm{~nm}$.

The EDX analyses shown in Tables 2 and 3 reveal that the spent catalyst contains, in addition to Co, Mo, and Al, small amounts of C; this finding was confirmed with the IR spectra.

The EDX analysis of the cobalt sulfide sample showed that, in addition to Co and $S$, the sample contains very small amounts of $\mathrm{Al}$ and the expected amount of $\mathrm{C}$. This result may be due to the adsorption of oxalic acid on the cobalt centers, as will be described in the analysis of the IR spectra.

3.3. Infrared Spectra. The infrared spectra of the spent catalyst and all of the extracted metals are shown in Figure 4 and are compared with the IR spectrum of oxalic acid.

The IR spectra of the extracted samples clearly show that some organic matrix was still adsorbed onto the samples. This matrix includes oxalic acid because the characteristic carbonyl peak $(\mathrm{C}=\mathrm{O})$ of oxalic acid at $1650 \mathrm{~cm}^{-1}$ appeared in nearly all of the samples. In addition, the spent catalyst itself 
TABLE 4: Data used for the simulation of the cobalt oxalate sulfide intermediate.

\begin{tabular}{|c|c|c|c|}
\hline Structure & Name & Energy $(\mathrm{KJ} / \mathrm{mol})$ & $\begin{array}{c}\text { Simulated visible } \\
\text { absorption Wavelength }\end{array}$ \\
\hline & $\begin{array}{l}\text { Carboxy arbonyloxy mercapto } \\
\text { (cobalt intermediate) }\end{array}$ & -1188.7 & $582.49 \mathrm{~nm}$ \\
\hline 8 & Cobalt oxalate & -919.04 & $382.84 \mathrm{~nm}$ \\
\hline * & Cobalt sulfide & -1911.836 & - \\
\hline
\end{tabular}

The red shifted wavelength of the intermediate indicates that it is responsible for the change in color from violet to red.

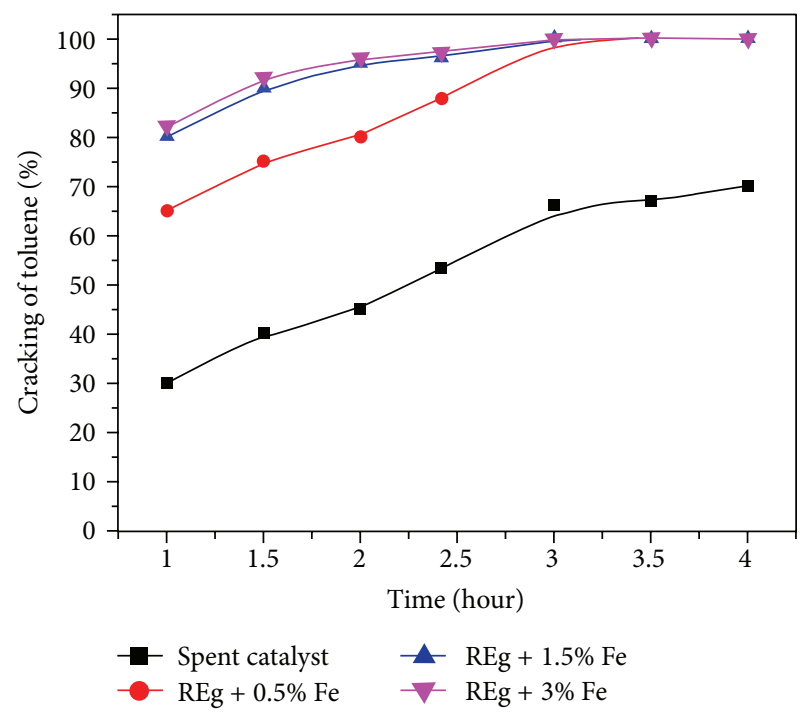

FIGURE 5: Catalytic activity of the spent catalyst with different iron oxide loadings in the cracking of toluene.

contains a trace $\mathrm{C}=\mathrm{O}$ peak, which may be due to the oxidation of the deposited coke on its surface during calcination.

3.4. Catalytic Activity. The effects of the loading of $0.5 \%, 1.5 \%$, and $3 \%$ iron on the regenerated catalyst were tested in the cracking of toluene. To achieve this, $100 \mathrm{~mL}$ of toluene and $1 \mathrm{~g}$ of the loading catalyst samples were heated at $100^{\circ} \mathrm{C}$ for $4 \mathrm{~h}$. The reaction product was then subjected to GC.

3.5. Extraction Mechanism and Sulfidization of Co. The extraction procedure depends on the formation of soluble oxalate complexes or compounds of all of the metals. The metals under investigation are $\mathrm{Al}, \mathrm{Co}$ and $\mathrm{Mo}$.

The equations in Scheme 1 represent the compounds and complexes formed by these metals.

Based on these equations, it is clear that oxalic acid forms soluble simple salts with $\mathrm{Al}$ and $\mathrm{Co}$ and oxocomplexes with Mo. In Scheme 1, we allowed for the possibility that both $\mathrm{Mo}(\mathrm{V})$ and $\mathrm{Mo}(\mathrm{VI})$ complexes can be formed.
The extraction method described in the experimental section leads to the precipitation of $\mathrm{Al}$ as $\mathrm{Al}(\mathrm{OH})_{3}$ and the separation of Mo as oxalate complexes. In contrast, Co is subjected to sulfidization by $\mathrm{H}_{2} \mathrm{~S}$. During this process, the color change from violet to red is followed by the formation of a black precipitate. The mechanism in Scheme 2 was assumed.

3.6. Mechanism of the Precipitation of CoS. The mechanism In Scheme 2 assumes that cobalt oxalate, which exhibits a violet color, is formed first. As a result of the subsequent reaction with $\mathrm{H}_{2} \mathrm{~S}$, a mercapto intermediate with a red color is formed and precipitated as CoS (black precipitate).

A simulation of the energy and electronic spectra of cobalt oxalate, cobalt sulfide, and the proposed intermediate was performed to prove the previous mechanism (Table 4).

Cracking activity toward toluene was shown in Figure 5. Figure 5 compares the catalytic activity of the spent catalyst with different loadings of iron oxide in the cracking of toluene. The curve demonstrates that the addition of iron oxide enhanced the catalytic activity of the spent catalyst. Moreover, the results show that the activity of the spent catalyst does not exceed $70 \%$ even after 4 hours. In contrast, the addition of $0.5 \mathrm{wt} \%$ iron oxide enhanced the catalytic activity to $100 \%$ after 3 hours. An additional increase in the loading of iron resulted in an increase in the catalytic activity of the spent catalyst. However, the addition of $1.5 \mathrm{wt} \%$ iron oxide resulted in almost the maximum increase that was observed; the addition of higher amounts of iron oxide resulted in only a slight excess in the catalytic activity of the catalyst.

These results show that the spent catalyst can be used for other purposes. Accordingly, its reuse instead of disposal could be an environmentally friendly alternative. The addition of a small amount of a different metal oxide, such as iron oxide, can enhance its catalytic activity, which maximizes the benefit of the spent catalyst.

\section{Conclusions}

The following conclusions can be drawn from this study.

(1) Oxalic acid efficiently dissolves the studied spent catalyst at a concentration of $0.1 \mathrm{~mol}$ per gram of catalyst. 
(2) A mechanism for the sulfidization of cobalt was proposed, and an intermediate was identified and confirmed.

(3) All of the metals were able to adsorb oxalic acid.

(4) $\mathrm{S}_{8}$ is formed during the precipitation of cobalt sulfide.

(5) In addition to the economic benefits of the extraction of metals from the spent catalyst, CoS itself can catalyze many reactions.

(6) The use of the spent catalyst as a catalyst for the removal of an industrial pollutant, such as toluene, was successfully performed.

(7) The catalytic activity of the spent catalyst in the cracking of toluene was enhanced by the simple impregnation of iron over the spent catalyst. The resulting ironloaded catalyst exhibited high performance and good catalytic activity (the resulting activity reached almost $100 \%)$.

\section{Acknowledgments}

This paper was funded by the Deanship of Scientific Research (DRS) of King Abdulaziz University, Jeddah (Grant no. 1-247D1432). The authors therefore acknowledge the DRS for the technical and financial support.

\section{References}

[1] Z. H. Eman, Evaluation and recycling of metals from spent catalyst due to hydrotreating process [M.S. thesis], Tanta University, Tanta, Egypt, 2003.

[2] D. Mishra, G. R. Chaudhury, D. J. Kim, and J. G. Ahn, "Recovery of metal values from spent petroleum catalyst using leachingsolvent extraction technique," Hydrometallurgy, vol. 101, no. 1-2, pp. 35-40, 2010.

[3] P. K. Parhi, K. H. Park, H. I. Kim, and J. T. Park, "Recovery of molybdenum from the sea nodule leach liquor by solvent extraction using Alamine 304-I," Hydrometallurgy, vol. 105, no. 3-4, pp. 195-200, 2011.

[4] B. B. Kar, P. Datta, and V. N. Misra, "Spent catalyst: secondary source for molybdenum recovery," Hydrometallurgy, vol. 72, no. 1-2, pp. 87-92, 2004.

[5] K. H. Park, D. Mohapatra, and C. W. Nam, "Two stage leaching of activated spent HDS catalyst and solvent extraction of aluminium using organo-phosphinic extractant, Cyanex 272," Journal of Hazardous Materials, vol. 148, no. 1-2, pp. 287-295, 2007.

[6] R. M. Gholami, S. M. Borghei, and S. M. Mousavi, "Bacterial leaching of a spent Mo-Co-Ni refinery catalyst using Acidithiobacillus ferrooxidans and Acidithiobacillus thiooxidans," Hydrometallurgy, vol. 106, no. 1-2, pp. 26-31, 2011.

[7] D. Mishra, D. J. Kim, D. E. Ralph, J. G. Ahn, and Y. H. Rhee, "Bioleaching of vanadium rich spent refinery catalysts using sulfur oxidizing lithotrophs," Hydrometallurgy, vol. 88, no. 1-4, pp. 202-209, 2007.

[8] D. Pradhan, J. G. Ahn, D. J. Kim, and S. W. Lee, "Effect of $\mathrm{Ni}^{+2}, \mathrm{~V}^{+4}$, and $\mathrm{Mo}^{+6}$ concentrations on iron oxidation by Acidithiobacillus ferrooxidnas," Korean Journal of Chemical Engineering, vol. 26, pp. 736-741, 2009.
[9] D. Pradhan, D. Mishra, D. J. Kim, J. G. Ahn, G. R. Chaudhury, and S. W. Lee, "Bioleaching kinetics and multivariate analysis of spent petroleum catalyst dissolution using two acidophiles," Journal of Hazardous Materials, vol. 175, pp. 267-273, 2010.

[10] L. Zeng and C. Y. Cheng, "A literature review of the recovery of molybdenum and vanadium from spent hydrodesulphurisation catalysts. Part I: metallurgical processes," Hydrometallurgy, vol. 98, no. 1-2, pp. 1-9, 2009.

[11] D. M. Pasquariello, R. Kershaw, J. D. Passaretti, K. Dwight, and A. Wold, "Low-temperature synthesis and properties of $\mathrm{Co}_{9} \mathrm{~S}_{8}$, $\mathrm{Ni}_{3} \mathrm{~S}_{2}$, and Fe7S8," Inorganic Chemistry, vol. 23, no. 7, pp. 872874, 1984.

[12] S. Miyazaki, M. Shirai, and N. Suzuki, "Electronic band structure of antiferromagnetic spinel Co3S4," Journal of Magnetism and Magnetic Materials, vol. 177-181, no. 2, pp. 1367-1368, 1998.

[13] E. Hillerova and C. Czech, "Activity and selectivity of carbon-supported transition metal sulfides in simultaneous hydrodearomatization and hydrodesulfurization," Collection of Czechoslovak Chemical Communications, vol. 54, pp. 26482656, 1989.

[14] J. P. Ge and Y. D. Li, "Controllable CVD route to CoS and MnS single-crystal nanowiresf," Chemical Communications, vol. 9, no. 19, pp. 2498-2499, 2003.

[15] H. Emadi, M. Salavati-Niasari, and F. Davar, "Synthesis and characterization of cobalt sulfide nanocrystals in the presence of thioglycolic acid via a simple hydrothermal method," Polyhedron, vol. 31, pp. 438-442, 2012.

[16] P. Barret, J. C. Closon, and D. Delefosse, Comptes Rendus De L Academie Des Sciences Serie Ii Fascicule C, vol. 262, p. 83, 1966.

[17] M. Salavati-Niasari, F. Davar, and M. R. Loghman-Estarki, "Controllable synthesis of thioglycolic acid capped $\mathrm{ZnS}(\mathrm{Pn}) 0.5$ nanotubes via simple aqueous solution route at low temperatures and conversion to wurtzite $\mathrm{ZnS}$ nanorods via thermal decompose of precursor," Journal of Alloys and Compounds, vol. 494, no. 1-2, pp. 199-204, 2010.

[18] M. Salavati-Niasari, A. Sobhani, and F. Davar, "Synthesis of starshaped $\mathrm{PbS}$ nanocrystals using single-source precursor," Journal of Alloys and Compounds, vol. 507, no. 1, pp. 77-83, 2010.

[19] M. Salavati-Niasari, F. Davar, and M. R. Loghman-Estarki, "Long chain polymer assisted synthesis of flower-like cadmium sulfide nanorods via hydrothermal process," Journal of Alloys and Compounds, vol. 481, no. 1-2, pp. 776-780, 2009.

[20] M. Salavati-Niasari, D. Ghanbari, and F. Davar, "Synthesis of different morphologies of bismuth sulfide nanostructures via hydrothermal process in the presence of thioglycolic acid," Journal of Alloys and Compounds, vol. 488, no. 1, pp. 442-447, 2009.

[21] M. Salavati-Niasari, M. R. Loghman-Estarki, and F. Davar, "Controllable synthesis of nanocrystalline CdS with different morphologies by hydrothermal process in the presence of thioglycolic acid," Chemical Engineering Journal, vol. 145, no. 2, pp. 346-350, 2008.

[22] X. F. Qian, X. M. Zhang, C. Wang, Y. Xie, and Y. T. Qian, "The preparation and phase transformation of nanocrystalline Cobalt sulfides via a toluene thermal process," Inorganic Chemistry, vol. 38, pp. 2621-2623, 1999.

[23] J. H. Zhan, Y. Xie, X. G. Yang, W. X. Zhang, and Y. T. Qian, "Hydrazine-assisted low-temperature hydrothermal preparation of nanocrystalline Jaipurite," Journal of Solid State Chemistry, vol. 146, no. 1, pp. 36-38, 1999.

[24] F. Ackermann, G. Berrebi, P. Dufresne, A. Van Lierde, and M. Foguenne, "French Patent EP 555128A1 930811," 1994. 

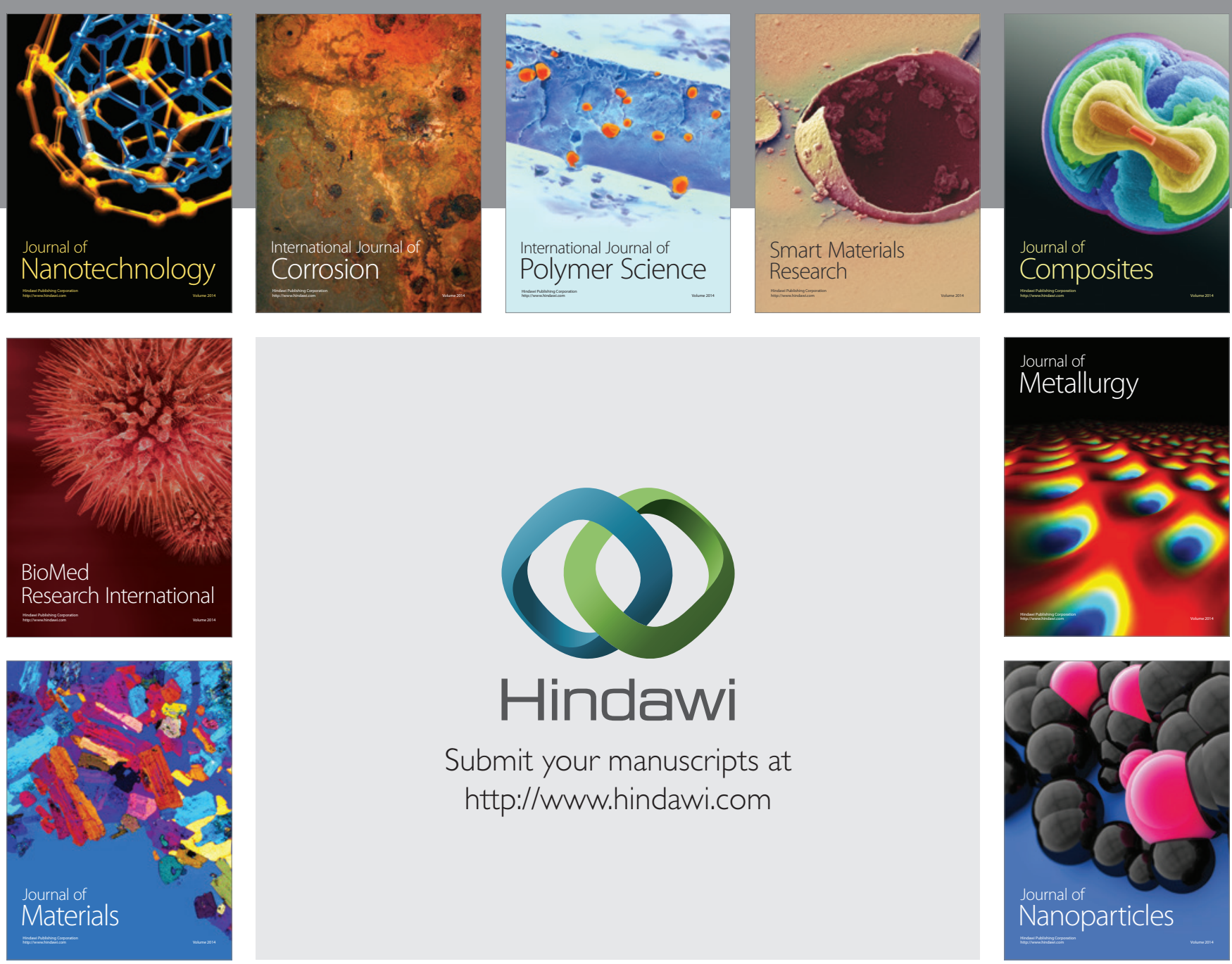

Submit your manuscripts at http://www.hindawi.com
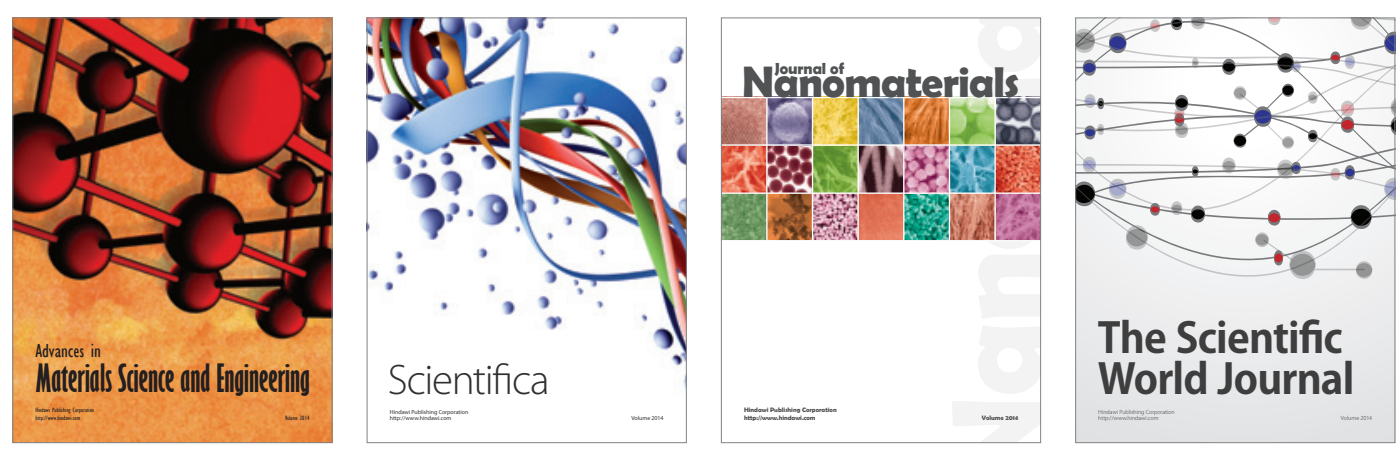

\section{The Scientific World Journal}
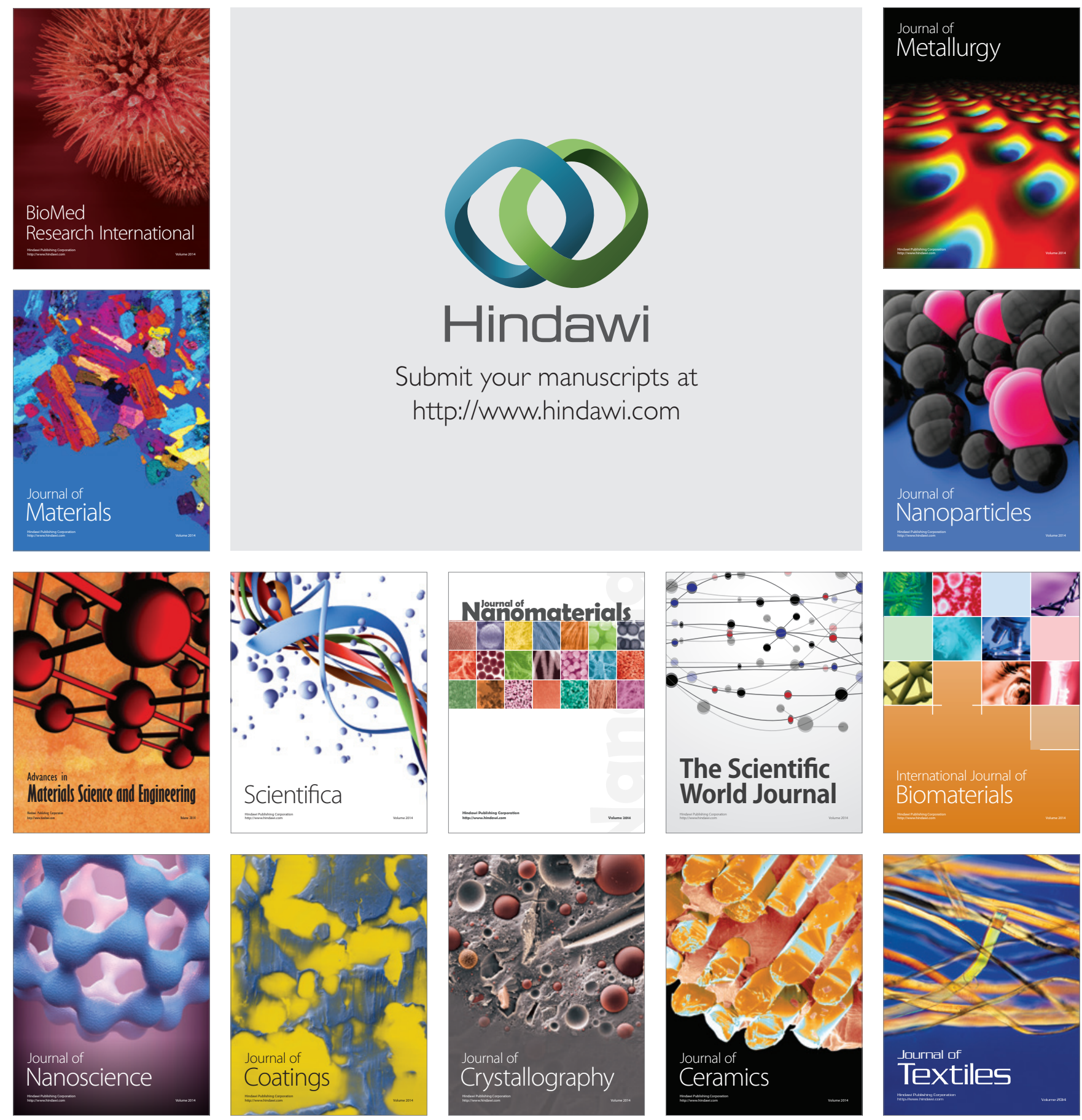